\title{
Sobre Gymnocerus Audinet-Serville, 1835 (Coleoptera, Cerambycidae, Lamiinae, Anisocerini) e gêneros relacionados
}

\author{
Carlos Eduardo de Alvarenga Julio ${ }^{1,2}$
}

\begin{abstract}
Aвstract. On Gymnocerus Audinet-Serville, 1835 (Coleoptera, Cerambycidae, Lamiinae, Anisocerini) and related genera. The genus Gymnocerus Audinet-Serville, 1835 is characterized and a key to the related genera is added. New combinations: Gymnocerina cratosomoides (Bates, 1862), comb. nov. (from Gymnocerus) and Badenella gavisa (Lane, 1966), comb. nov. (from Chimboincola). New synonyms proposed: Badenella Lane, 1964 = Chimboincola Lane, 1966 syn. nov.; Gymnocerina cratosomoides (Bates, 1862) = Gymnocerus crassus Bates, 1862 syn. nov. = Gymnocerina sulfurea Lane, 1964 syn. nov. = Gymnocerina subsiciva Lane, 1964 syn. nov. $=$ Gymnocerina spuria Lane, 1964 syn. nov. $=$ Gymnocerina oliveirai Lane, 1964 syn. nov.; and Badenella badeni (Bates, 1875) = Gymnocerus badeni fuscus Franz, 1935 syn. nov. = Badenella laceyi Lane, 1964 syn. nov..
\end{abstract}

KeYwords. Anisocerini; Gymnocerus; Lamiinae; Neotropical; taxonomy.

\section{INTRODUÇÃO}

Desde que Gymnocerus foi estabelecido por AudinetServille (1835: 84) para G. scabripennis (Fig. 1), diversas espécies foram incluídas, ou para ele transferidas, apesar de possuírem caracteres que as afastavam da espécie-tipo. BATES (1862) foi o primeiro autor a descrever e transferir espécies para o gênero. Assinalou que ambos os sexos possuem onze antenômeros e que, segundo Audinet-Serville, os machos possuem o antenômero XI muito longo. Comentou, ainda, que "amongst the species wich I propose to include in the genus, some have this joint as long as the tenth, others much shorter; and it is always relatively shorter in the female than in the male. All the joints are naked; but the third in some species, and the fourth in others, are more or less thickened at the tip". A partir de então várias espécies foram descritas no gênero, algumas estreitamente relacionadas, porém distantes da caracterização de Gymnocerus, representado por G. scabripennis. Por esta razão, LANE $(1964 ; 1966)$ erigiu alguns gêneros para espécies de Gymnocerus que não compartilhavam caracteres com a espécie-tipo, dentre os quais Badenella, Batesbeltia, Gounellea, Jurua, Gymnocerina e Chimboincola.

No presente artigo apresenta-se uma chave para identificação dos gêneros relacionados a Gymnocerus, que é caracterizado com base no diapositivo de G. scabripennis (Fig. 1), e propõem-se sinonímias e novas combinações em Badenella Lane, 1964 e Gymnocerina Lane, 1964.
O material examinado pertence às seguintes instituições: Departamento de Zoologia, Universidade Federal do Paraná, Curitiba (DZUP); Museu Nacional, Universidade Federal do Rio de Janeiro, Rio de Janeiro (MNRJ) e Museu de Zoologia, Universidade de São Paulo, São Paulo (MZSP). Os diapositivos foram feitos por J.S. Moure (DZUP) no Muséum National d'Histoire Naturelle, Paris (MNHN), American Museum of Natural History, Nova York (AMNH) e The Natural History Museum, Londres (BMNH).

Chave para os gêneros relacionados a Gymnocerus

1. Escapo fortemente clavado; antenômero XI, nos machos, tão ou mais longo que $\mathrm{o} X$ 2 Escapo moderadamente clavado; antenômero XI, nos machos, mais curto que o X. . .3

2(1). Escapo abruptamente recortado na face ventral da base; élitros com granulação na região centro-basal ....... 4

Escapo adelgaçado e sem recorte abrupto na face ventral da base; élitros granulados em toda a metade basal

3(1). Antenas curtas, não atingem os ápices elitrais; antenômero III não-espessado no ápice; élitros com o tubérculo centro-basal bastante protuberante, arredondado, liso e sem pubescência no topo;

\footnotetext{
1. Departamento de Entomologia, Museu Nacional, Universidade Federal do Rio Janeiro. Quinta da Boa Vista, São Cristóvão, 20940-040 Rio de Janeiro-RJ, Brasil. Endereço eletrônico: ceajulio@ig.com.br

2. Doutorando em Ciências Biológicas, Área de Concentração Zoologia, Instituto de Biociências, UNESP/Botucatu.
} 
úmeros salientes e granulados; metade apical dos élitros com cristas longitudinais alongadas e irregulares, a interna mais saliente

Gymnocerina Lane, 1964

Antenas longas, ultrapassam os ápices elitrais; antenômero III espessado no lado interno do ápice; élitros sub-lisos, sem tubérculos ou cristas, apenas granulados na região centro-basal; úmeros nãogranulados Gounellea Lane, 1964

4(2). Antenômero III curvo, fortemente intumescido no lado interno do ápice; élitros com a região centro-basal discretamente elevada e a metade apical sem carenas Batesbeltia Lane, 1964

Antenômero III reto, sem intumescência apical; élitros com tubérculo centro-basal manifesto e com duas carenas curvas que convergem no terço apical

Badenella Lane, 1964

5(2). Antenas ultrapassam os ápices elitrais a partir do antenômero V; antenômero XI subigual ao X em comprimento; élitros sem tubérculos ou cristas Jurua Lane, 1964 Antenas ultrapassam os ápices elitrais a partir do antenômero VII; antenômero XI mais longo que o $\mathrm{X}$; élitros com elevação centro-basal e na metade apical com cristas longitudinais curtas, a sutural mais proeminente ....... Gymnocerus Audinet-Serville, 1835

\section{Gymnocerus Audinet-Serville, 1835}

Gymnocerus Audinet-Serville, 1835: 84; Thomson, 1860: 33; 1864: 21, 352; Bates, 1862: 452; Lacordaire, 1872: 721; Monné, 1994: 7 (cat.).

Espécie-tipo: Gymnocerus scabripennis Audinet-Serville, 1835 (monotipia).

Lobos oculares superiores tão distantes entre si quanto o dobro da largura de um lobo. Antenas glabras, longas, ultrapassam, nos machos, os ápices elitrais a partir do antenômero VII; escapo robusto, clavado, adelgaçado na metade basal; antenômero III tão longo quanto o escapo + pedicelo; IV o mais longo; VI-VIII os mais curtos, subiguais em comprimento; IX e X tão longos quanto o V; antenômero XI mais longo que o precedente e curvo no ápice. Protórax unituberculado lateralmente; pronoto com gibosidades laterais manifestas. Élitros com elevação centro-basal granulada; metade basal do disco densamente recoberta por grânulos negros; metade apical com cinco cristas elevadas, curtas, a sutural mais proeminente; úmeros granulados e ápices arredondados.

Comentários. Com a transferência de duas espécies, o gênero fica restrito à espécie-tipo, G. scabripennis, proveniente de Cayenne (Guiana Francesa). O holótipo está depositado no MNHN.
Gymnocerina Lane, 1964

Gymnocerina Lane, 1964: 190; Monné, 1994: 9 (cat.).

Espécie-tipo: Gymnocerina oliveirai Lane, 1964 (designação original).

Fronte plana, com os lados divergentes para a região inferior e borda inferior reta; genas bastante alargadas na parte inferior nas fêmeas. Olhos grandes, lobos oculares superiores tão distantes entre si quanto a largura de um lobo. Tubérculos anteníferos bastante separados, não-projetados. Antenas delgadas, glabras, atingem, aproximadamente, o terço apical dos élitros nos machos e o meio destes nas fêmeas; escapo moderadamente clavado na metade apical e adelgaçado na base, subigual ao antenômero III em comprimento; antenômeros IV$\mathrm{X}$ gradualmente decrescentes em comprimento; o XI com um terço do comprimento do X.

Protórax com um tubérculo cônico de cada lado; pronoto sem tubérculos distintos, com uma pequena elevação centrobasal; processo mesosternal bituberculado e escavado no centro. Élitros esparsa e profundamente pontuados na metade basal, com um tubérculo centro-basal bastante protuberante, com o topo arredondado, liso, sem pubescência ou grânulos; metade apical com três cristas longitudinais alongadas e irregulares, a interna mais saliente, que não alcançam a margem elitral; úmeros proeminentes e granulados e ápices arredondados.

Fêmures clavados, nos machos os anteriores e médios mais fortemente; tíbias anteriores gradualmente alargadas para o ápice; protarsos franjados nos machos.

Urosternito $\mathrm{V}$ das fêmeas com pequeno sulco no centro da metade basal.

Comentários. Distingue-se de Gymnocerus pelos lobos oculares superiores tão distantes entre si quanto a largura de um lobo; pelas antenas dos machos, curtas, atingem, aproximadamente, o terço apical dos élitros; pelo escapo moderadamente clavado na metade apical e adelgaçado na base, subigual ao antenômero III em comprimento; pelos antenômeros IV-X gradualmente decrescentes em comprimento e o XI com um terço do comprimento do X; pelo pronoto sem tubérculos distintos, com uma pequena elevação centro-basal e pelo aspecto da metade basal dos élitros, esparsa e profundamente pontuada, com um tubérculo centro-basal bastante protuberante, arredondado no topo, liso, sem pubescência ou grânulos. Em Gymnocerus: lobos oculares superiores tão distantes entre si quanto o dobro da largura de um lobo; antenas longas, nos machos ultrapassam os ápices elitrais a partir do antenômero VII; escapo robusto, clavado, adelgaçado na metade basal; antenômero III tão longo quanto escapo + pedicelo; IV o mais longo; VI-VIII os mais curtos, subiguais em comprimento; IX e X tão longos quanto o V e o antenômero XI mais longo que o X; pronoto com gibosidades laterais manifestas; metade basal dos élitros densamente recoberta por grânulos e com elevação centro-basal granulada.

Após as sinonímias propostas, o gênero fica restrito a uma espécie, G. cratosomoides, procedente do Amazonas (Brasil). 

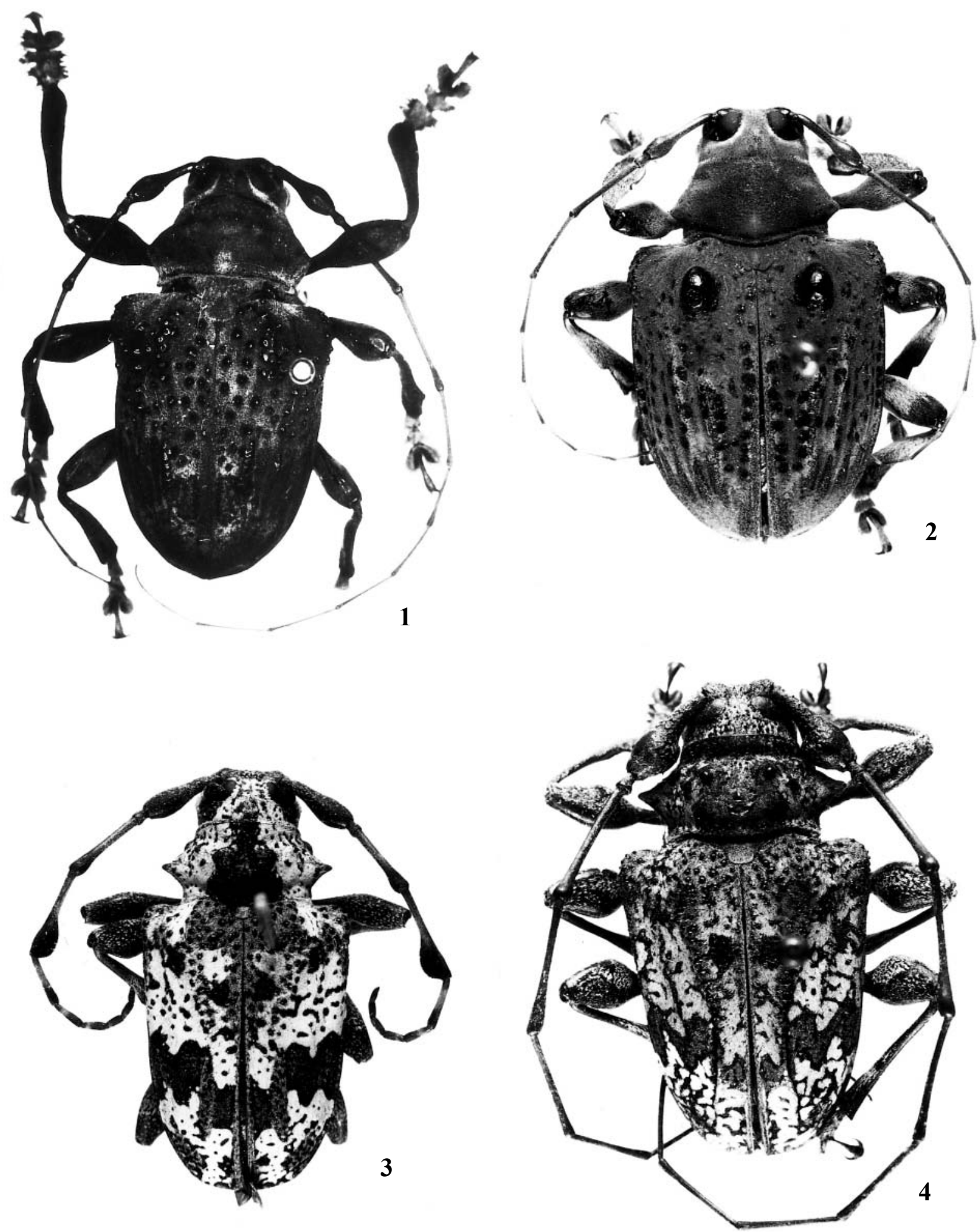

Figs. 1-4. 1, Gymnocerus scabripennis Audinet-Serville, 1835, holótipo macho, Cayenne, Guiana Francesa, reprodução do diapositivo obtido por J. S. Moure no MNHN; 2, Gymnocerina cratosomoides (Bates, 1862), macho, Benjamin Constant, Amazonas, Brasil, comprimento 19,0 mm; 3, Badenella gavisa (Lane, 1966), parátipo fêmea de Chimboincola gavisa, Chimbo, Equador, comprimento 14,2 mm; 4, Badenella badeni badeni (Bates, 1875), macho, Balzapampa (750 m), Equador, comprimento 19,0 mm. 
O holótipo está depositado no MNHN.

Gymnocerina cratosomoides (Bates, 1862) comb. nov.

(Fig. 2)

Gymnocerus cratosomoides Bates, 1862: 452; Lacordaire, 1872: 722; Haase, 1892: 17; Melzer, 1932: 222 (distr.); Monné, 1994: 7 (cat.). Gymnocerus crassus Bates, 1862: 453; Lacordaire, 1872: 722; Melzer, 1932: 222 (distr.); Monné, 1994: 7 (cat.). Syn. nov.

Gymnocerina oliveirai Lane, 1964: 191; Monné, 1994: 9 (cat.). Syn. nov.

Gymnocerina spuria Lane, 1964: 192; Monné, 1994: 9 (cat.). Syn. nov.

Gymnocerina subsiciva Lane, 1964: 192; Monné, 1994: 9 (cat.). Syn. nov.

Gymnocerina sulfurea Lane, 1964: 193; Monné, 1994: 9 (cat.). Syn. nov.

Os olhos grandes com os lobos oculares superiores tão distantes entre si quanto a largura de um lobo; as antenas curtas, atingindo, nos machos, aproximadamente, o terço apical dos élitros e, nas fêmeas, o meio destes, com o escapo moderadamente clavado na metade apical, adelgaçado na base e subigual ao antenômero III em comprimento, os antenômeros IV-X gradualmente decrescentes em comprimento e o XI com um terço do comprimento do X; o pronoto sem tubérculos distintos, com uma pequena elevação centro-basal e a metade basal dos élitros esparsa e profundamente pontuada, com um tubérculo centro-basal bastante protuberante, o topo arredondado, liso, sem pubescência ou grânulos, permitem posicionar Gymnocerus cratosomoides em Gymnocerina.

Bates (1862: 452) ao descrever Gymnocerus cratosomoides e G. crassus, ambos procedentes do Amazonas (Brasil), assinalou, referindo-se a $G$. crassus "this species very much resembles $G$. cratosomoides, and might be treated as a variety of it, although it seems more convenient to deal with it as a separate form". O exame de exemplares de G. cratosomoides e G. crassus, dos holótipos de Gymnocerina oliveirai, G. spuria e G. sulfurea e do diapositivo do holótipo de Gymnocerina subsiciva $(\mathrm{BMNH})$, permitiu propor as sinonímias acima. Os caracteres apontados por LANE (1964), que diferenciam $G$. oliveirai, G. spuria e G. subsiciva, baseiam-se, principalmente, na variação de coloração corporal e granulação na base dos élitros. A coloração distinta, "amarelo-sulfúrea, muito pálida", e o aspecto da cabeça, "na parte inferior extraordinariamente alargada nas genas", utilizados para distinguir G. sulfurea, são caracteres sexuais, já que foram utilizados apenas exemplares fêmeas na descrição da espécie.

Material examinado. BRASIL, Amazonas: Benjamin Constant, holótipo macho (Gymnocerina sulfurea), VII.1956, I.C. Lima col. (MNRJ), macho, II.1957, I.C. Lima col. (MNRJ); (Rio Javari), holótipo macho (Gymnocerina spuria), III.1942, A. Parko col. (MNRJ), fêmea, X.1960, macho, X.1961, macho, XI.1961, Diringshofen col. (MZSP); Manaus, macho, VIII.1941, A. Parko col. (MNRJ), macho, X.1957, macho, III.1958, C. Elias col. (DZUP); Tabatinga, holótipo macho (Gymnocerina oliveirai), III.1959, F.M. Oliveira col. (MNRJ); Tefé, macho, VIII.1921, J.F.Zikán col. (MZSP). Pará: Óbidos, parátipo fêmea (G. sulfurea), III.1958, F.M. Oliveira col. (MNRJ); Tucuruí, macho, I.1980, B. Silva col. (MNRJ). Rondônia: Vilhena, macho e fêmea, XI.1960, M. Alvarenga col. (MNRJ), macho e 2 fêmeas, XI.1973,
Alvarenga \& Roppa cols. (MNRJ)

\section{Badenella Lane, 1964}

Badenella Lane, 1964: 186; Monné, 1994: 7. Espécie-tipo: Gymnocerus badeni Bates, 1875 (designação original).

Chimboincola Lane, 1966: 237; Monné, 1994: 6. Espécie-tipo: Chimboincola gavisa Lane, 1966 (monotipia e designação original). Syn. nov.

LANE (1964) ao erigir Badenella utilizou caracteres das antenas (forma do escapo e do antenômero IV), do protórax e dos élitros (gibas basais e carenas) para distingui-lo de Gymnocerus. LANE (1966) utilizou estes mesmos caracteres distintivos ao estabelecer Chimboincola. O exame do material disponível, inclusive do parátipo fêmea de $C$. gavisa, permitiu propor a sinonímia entre Badenella e Chimboincola, com base nos seguintes caracteres: escapo fortemente clavado e abruptamente recortado na face ventral da base; antenômero IV espessado no lado interno do ápice; protórax com um tubérculo cônico e protuberante de cada lado; pronoto trituberculado; élitros com gibosidade centro-basal elevada e granulada e duas carenas, curvas, que convergem no terço apical, a interna mais marcada.

Comentários. Após as transferências e sinonímias propostas, o gênero passa a reunir quatro espécies: $B$. badeni (Bates, 1875), localidade-tipo Frontino (Colômbia), holótipo depositado no MNHN; B. gavisa (Lane, 1966), localidade-tipo Chimbo (Equador), holótipo depositado no MNHN; $B$. fallaciosa Lane, 1964, localidade-tipo Colômbia, holótipo depositado no Zoologische Staatssammulung des Bayerischen Staates, Munich; B. ignota Lane, 1964, localidade-tipo Colômbia, holótipo depositado no University Museum, Hope Entomological Collection, Oxford.

\section{Badenella gavisa (Lane, 1966) comb. nov.} (Fig. 3)

Chimboincola gavisa Lane, 1966: 238; Monné, 1994: 7 (cat.).

Material examinado. EQUADOR, Chimbo, parátipo fêmea (de Chimboincola gavisa), 1897, M. de Mathan col. (MZSP); Pichincha: Santo Domingo de los Colorados, macho e fêmea, I.1982 (MNRJ), 3 machos e 2 fêmeas, III.1982 (MNRJ), macho e 2 fêmeas, VIII.1982 (MNRJ).

\section{Badenella badeni (Bates, 1875)}

(Fig. 4)

Gymnocerus badeni Bates, 1875: 276; Lameere, 1883: 65 (cat.); Franz, 1935: 170 , figs $2 \mathrm{a}, \mathrm{b}$.

Badenella badeni; Lane, 1964: 187.

Badenella badeni badeni; Monné, 1994: 7 (cat.).

Gymnocerus badeni fuscus Franz, 1935:171, fig. 2c. Syn. nov.

Badenella badeni fuscus; Monné, 1994:7 (cat.).

Badenella laceyi Lane, 1964: 189; Monné, 1994: 8 (cat.). Syn. nov.

LANE (1964: 189) ao descrever B. laceyi comentou que esta espécie "é próxima de badeni, da qual se distingue pela 
angulosidade de contorno da faixa parda transversa dos élitros e pela ausência quase completa de desenhos escuros, estes reduzidos às pequenas manchas irregulares pardo-arroxeadas, de cada lado da sutura, abaixo das gibas basais. Estruturalmente, as antenas são um tanto mais robustas e a área basal dos élitros mais densamente granulosa, os grânulos invadindo os desenhos vagos cordiformes". Franz (1935:171) considerou como caracteres distintivos, na descrição de G. badeni fuscus, a coloração aparentemente mais escura da superfície corporal, o aspecto mais proeminente dos tubérculos pronotais e a base dos élitros mais densamente granulosa. Com o exame dos exemplares disponíveis, dos diapositivos do lectótipo de Gymnocerus badeni (MNHN) e do holótipo de Badenella laceyi (AMNH) e da descrição original e ilustração de G. badeni fuscus, verificou-se que as diferenças apontadas são apenas pequenas variações cromáticas e estruturais, permitindo, portanto, propor as sinonímias acima.

Material examinado: COLÔMBIA, San Antônio, macho e fêmea (MZSP). EQUADOR, Balzapampa (750 m), macho, Campos col. (MNRJ); Cotopaxi: San Francisco de las Pampas, macho, II.1993, L. Bartolozzi col. (MNRJ); Pichincha: Santo Domingo de los Colorados, 2 machos, III.1982 (MNRJ e MZSP), macho, VII.1982 (MNRJ).

Agradecimentos. Ao Dr. Miguel A. Monné (MNRJ) pelas sugestões e revisão do manuscrito; aos Drs Ubirajara R. Martins (MZSP) e Renato C. Marinoni (DZUP) pelo empréstimo de material e dos diapositivos; ao Prof. Johann Becker (MNRJ) pela tradução dos originais em alemão; a Sérgio Barbosa Gonçalves pela execução das fotografias e à Fundação de Amparo à Pesquisa do Estado de São Paulo (FAPESP, Proc. no 98/106925) pela bolsa de Doutorado concedida.

\section{REFERÊNCIAS}

Audinet-Serville, J. G. 1835. Nouvelle classification de la famille des longicornes. Annales de la Société Entomologique de France 4(1): 5-100.

Bates, H. W. 1862. Contributions to an insect fauna of the Amazon Valley. Coleoptera. Longicornes. Annals and Magazine of Natural History 9(3): 446-458.

Bates, H. W. 1875. New genera and species of longicorns from South America. Entomologist's Monthly Magazine 11: 273-278.

Franz, E. 1935. Neues zur Gattung Gymnocerus Serv. (Col.,Cerambycidae). Entomologische Rundschau 52: 169-172.

HAASE, E. 1892. Untersuchungen über die mimicry auf Grundlagen einer naturlichen Systems der Papilioniden. Zweiter Theil: Untersuchungen über die Mimicry. Bibliotheca Zoologica 8: 1-161.

Lacordaire, J. T. 1872. Histoire Naturelle des Insectes. Genera des Coléoptères. Paris, Roret 9(2): 411-930.

Lameere, A. A. 1883. Liste des cérambycides, décrits postérieurement au catalogue de Munich. Annales de la Société Entomologique de Belgique 26: 1-78.

Lane, F. 1964. Novos gêneros e espécies de Anisocerini (Coleoptera, Lamiidae). Studia Entomologica 7: 179-200.

Lane, F. 1966. Novos gêneros e espécies de Anisocerini II (Coleoptera, Lamiidae). Papéis Avulsos do Departamento de Zoologia 18(20): 237-243.

Melzer, J. 1932. Vinte espécies novas de cerambycideos neotrópicos, principalmente do Brasil. Revista de Entomologia 2(2): 216-238.

MonNÉ, M. A. 1994. Catalogue of the Cerambycidae (Coleoptera) of the Western Hemisphere. Part XVII. São Paulo, Sociedade Brasileira de Entomologia, $110 \mathrm{p}$.

Тномson, J. 1860. Essai d'une classification de la famille des cérambycides et matériaux pour servir a une monographie de cette famille. Paris, $404 \mathrm{p}$.

Thomson, J. 1864. Systema cerambycidarum ou exposé de tous les genres compris dans la famille des cérambycides et familles limitrophes. Mémoires de la Société Royale de Sciences de Liège 19: 1540 . 